\title{
Management of Postpartum Prolapse of Uterus in Cross Breed Cow
}

\author{
Bedanta Pathak $^{1 *}$, Anurag Borthakur ${ }^{2}$ and Utpal Barman ${ }^{3}$ \\ ${ }^{1}$ Krishi Vigyan Kendra, Karimganj, Assam Agricultural University, Jorhat-13, India \\ ${ }^{2}$ College of Veterinary Science, Assam Agricultural University, Khanapara, Ghy-22, India \\ ${ }^{3}$ Teaching Veterinary Clinical Complex, College of Veterinary Science, \\ Khanapara, Ghy-22, India \\ *Corresponding author
}

\section{A B S T R A C T}

\begin{tabular}{|l|}
\hline Ke y w o r d s \\
$\begin{array}{l}\text { Jersey cow, } \\
\text { Supportive } \\
\text { treatment, Suture, } \\
\text { Uterine prolapse }\end{array}$ \\
\hline Article Info \\
\hline $\begin{array}{l}\text { Accepted: } \\
17 \text { August } 2020 \\
\text { Available Online: } \\
\text { 10 September } 2020\end{array}$ \\
\hline
\end{tabular}

The present case is related to post- partum uterine prolapse in a jersey cow which frequently occurs due to a variety of reasons. In this case, the uterine prolapse was observed $2 \mathrm{hrs}$ after delivery showing protrusion of an extensive mass of the uterus with profuse bleeding. On examination, the uterus was swollen and inflamed, with cotyledons and caruncles visible over the uterine mass. The endometrium was washed with $\mathrm{KMNO}_{4}(1: 1000)$ followed by application of ice and hypertonic solution to reduce the size of uterus. The uterus was lifted and pushed back into its right position with gentle pushing using fisted hand while holding it in position with the other hand. Tetracycline boli and Metrogyl solution were inserted intra uterine and then sutured to keep the uterus in place. Supportive treatment was instituted for a period of one (1) week.

\section{Introduction}

Uterine prolapse is most commonly reported in pluriparous dairy cows, even though its occurrence is widespread affecting all animal species (Roberts, 1986). Uterine prolapse occurs mainly after parturition when the intraabdominal pressure is high (Bhattacharyya et al., 2007). Compared to the vaginal prolapse, the uterine prolapse is larger, longer (usually hanging down to the hocks when standing), deep red in colour and covered with the "buttons" where the placenta was attached (Ward and Powell, 2005). Poor myometrial contractions during the post-partum period and traction during difficult births are two postulated etiologies of uterineprolapse (Purohit et al., 2018). Hypocalcaemia results in myometrial fatigue and delays the cervical involution turning out to be yet another factor for uterine prolapse (Kasturi et al., 2017). High level of blood estrogen has also been ascribed to uterine prolapse (Meisner and Anderson, 2008). Deficiency of calcium, phosphorus and magnesium levels in the last period of pregnancy and at the parturition are some of the possible causes of post parturient uterine prolapse in cows (Al- Saeed et al., 2017). 


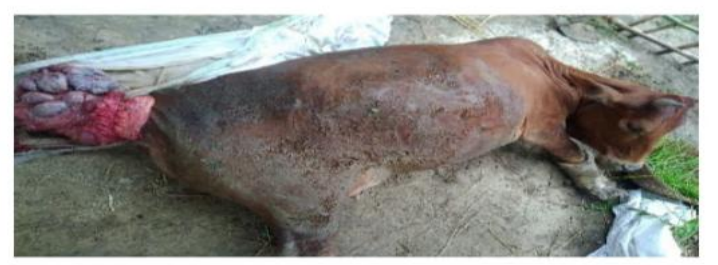

Figure 1: Prolapse of the uterus following parturition

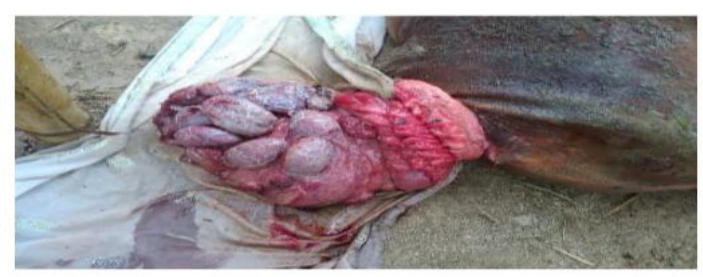

Figure 2: Cotyledons visible over the uterine mass

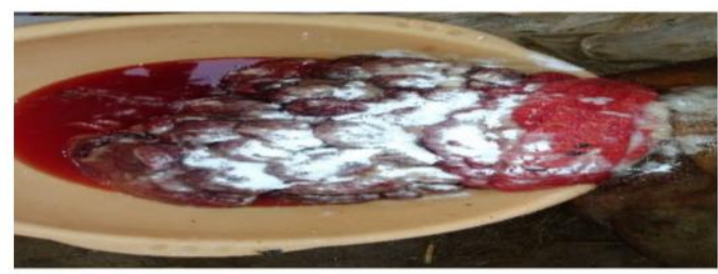

Figure 3: Massive bleeding following uterine prolapse

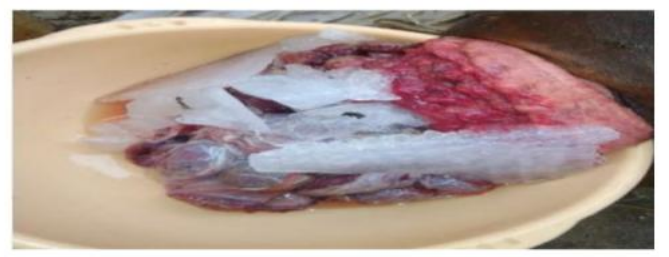

Figure 4: Cleaning of the uterus with KMNO4 and application of ice.

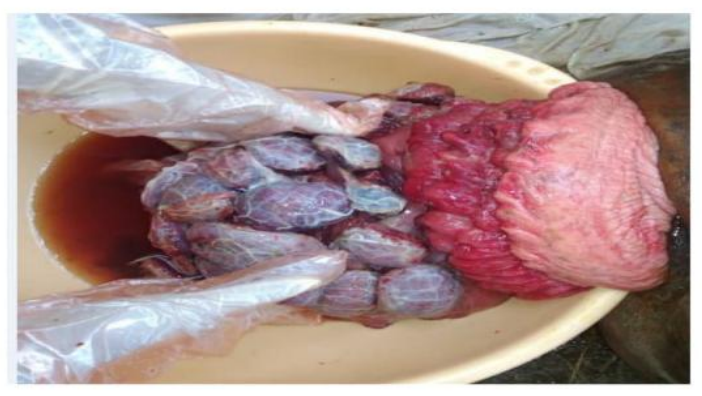

Figure 5: Shrunken uterine mass after application of ice and hypertonic solution

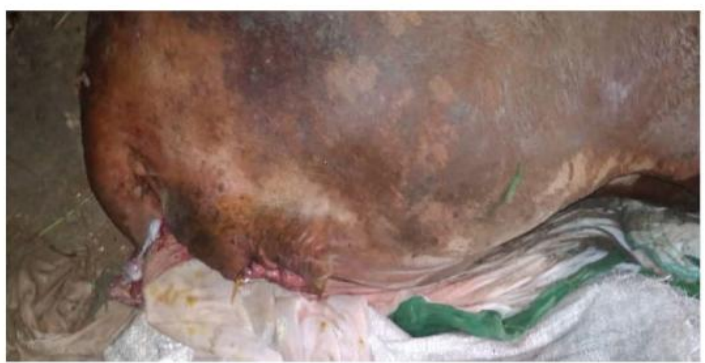

Figure 6: Buhner's suture after placing the uterine mass to its normal position. 
In cows, treatment involves removing the placenta (if still attached), thoroughly cleaning the endometrial surface, and repairing any lacerations. Rubbing the surface of the uterus with glycerol helps reduce oedema and provides lubrication. The uterus is then returned to its normal position (Gilbert, 2015) Buhner's suture is the most effective way to keep the uterus in position and is removed after a week's time when the uterus is settled in its position (Hasan et al., 2017). Supportive treatment is instituted to minimize the chances of infection and also enhance the immunity of the animal.

\section{Clinical management}

A clinical case of uterine prolapse was reported in a 3 and $1 / 2$ year old jersey cross cow in Nagaon District of Assam, India. Ten days prior to parturition, there was a fracture in the right forelimb below the knee joint, which was surgically repaired with Plaster of Paris (POP) and was showing signs of healing. However, post parturition, there were some complications marked by massive bleeding, further followed by prolapse of the uterus just two hours from the time of delivery (Figure 1 and 3). The new-born calf was healthy and responded positively to all the vital signs. The Uterus was soiled and inflamed, the caruncles and cotyledons were clearly visible on the surface of the uterus. (Figure 2) The uterus was properly cleaned with water and anti-septic spray, $\mathrm{KMNO}_{4}$ (1:1000) was also used to remove all kinds of dirt and germs from the uterus (Figure 4). Application of ice and hypertonic solution was done to reduce the inflammation and cause shrinkage to the uterus. Reduction of prolapsed mass was one of the goals of the treatment to facilitate repositioning of the uterus in its place. Caudal epidural block was achieved by injecting $10 \mathrm{ml}$ of $2 \%$ lignocaine in the sacrococcygeal intervertebral space. The uterine mass was lifted to allow for urination and was gently repositioned using pressure of the fist while holding it up with the palm of the other hand (Figure 5). Two tetracycline boli and50 $\mathrm{ml}$ Metrogyl solution were administered intra uterine to reduce the chances of infection. Once the uterus was pushed back into position, Buhner's suture was applied around the vulva as a form of support to the uterus (Figure 6). The suture was removed after a period of 1 week. Postoperative treatment was followed for a period of 1 week to prevent the occurrence of infection. $500 \mathrm{ml}$ of Ringer's lactate was infused IV on alternate days for three occasions. Intacef (Ceftriaxone) was administered IV at the dose rate of $10 \mathrm{mg} / \mathrm{kg}$ body weight for 5 days. Tribivet $(10 \mathrm{ml})$ was given IM as supportive therapy. $10 \mathrm{ml}$ melonexinj was administered IM for pain relief and was given twice on alternate days.

\section{References}

Al-Saeed., A.H.N., Abd., S.A. and Al-maliki., S.G. (2017). A comparison between prolapse and mineral deficiency in Iraqi local cattle and buffalo cows (Bubalus bubalis). Research Journal of life sciences, Bioinformatics, Pharmaceutical and Chemical sciences, 2(5): 32-40

Bhattacharyya., H.K., Peer., F.U., Buchoo., B.A. and Ansari., M.M. (2007). Management of uterine prolapse in cattle. Indian veterinary journal, 84 (7):744-745.

Gilbert., R.O. (2015) Overview of Uterine Prolapse and Eversion. Merk's Veterinary Manual.

Hasan., T., Azizunnesa., P.M., Paul., P., Akter., S., Faruk., M.O. and Hossain., D. (2017). Correction and management of vaginal prolapse in a cow by Buhner's technique. Research Journal of Veterinary Practitioner, 5(1):1-4.

Kasturi., N., Selvaraju., M. and Sendilvelan., 
S.(2017). Uterine Prolapse in a JerseyRed Sindhi Cross Cow. Research Journal of Pharmaceutical Biological and Chemical sciences, 8(1): 10391042 .

Miesner., M.D. and Anderson., D.E. (2008). Management of uterine and vaginal prolapse in the bovine. Veterinary Clinics of North America. Food Animal Practice, 24: 409-419

Purohit., G.N., Arora., A.S., Gocher., T., Gaur., M., Saraswat., C.S. and Mishra., P. (2018) Uterine prolapse in buffaloes: A review. Asian Pacific Journal of Reproduction, 7(6): 241.

Roberts., S.J. (1986): 11 injuries and diseases of the puerperal period. In: Roberts SJ (ed.): Veterinary Obstetrics and Genital Diseases. 3rd ed. Vermont, Woodstock. Pp. 353-397.

Ward., H., Powell., J. (2005) Reproductive prolapsed of cattle. Agriculture and Natural Resources. University of Arkansas system.

\section{How to cite this article:}

Bedanta Pathak, Anurag Borthakur and Utpal Barman. 2020. Management of Postpartum Prolapse of Uterus in Cross Breed Cow. Int.J.Curr.Microbiol.App.Sci. 9(09): 2402-2405. doi: https://doi.org/10.20546/ijcmas.2020.909.300 